\title{
Critical Quarterly for Legislation and Law (EuCritQ)
}

\author{
Europe as a "starting point and object of critical observation"
}

\section{Objects and Approaches of Critique}

In 1986, the editors of the "Critical Quarterly for Legislation and Law (CritQ)" - with publication re-starting after a 40 year break - professed the aims of the young magazine that at the same time enjoyed a long tradition. It was to be the forum for open, interdisciplinary-oriented, intradisciplinary-informed critical jurisprudence grounded in the theory-praxis dialogue. Since then, the CritQ has repeatedly shown itself to be more than a "collection of articles and decisions" from various disciplines. It was always at the cutting edge of legal policy without being opportunistic. It remained sensitive to the deficits in the legal system and described the dramatic change of its controlling functions, including the destruction of individual liberties which often went along with this change, without falling into a lament. The critique was biting without being destructive. These characteristics have made it an important medium in the German-speaking discourse for all who wish to think beyond the dogmatic limitations of legal science. It is this critical approach that is to be cultivated.

It is also to be expanded, however. Objects of critique change, and the changes in objects require a corresponding change in the communication of critique. The legal system, once tied to national boundaries, has been differentiated both vertically and horizontally. The vertical movement has occurred because hierarchies of norms are being created and established beyond the state orders. International law binds states' legal systems into an international legal order, and community law claims priority over national norms. Human rights, interpreted and applied by international courts, affect state law and remind it of its responsibilities. The horizontal movement has occurred because sub-systems of European and international law are partially linked to each other and yet at times partially compete with each other. The classic separation of legal sciences into the disciplines of civil law, public law, and penal law, is increasingly breaking down. System control using law makes use of individual elements of these disciplines and puts them together in a new and different way. The highest judicial controls are developing in the form of a dialogue between trans-national and state legal organs. They make up the framework of legal protection around the horizontally differentiated legal system. In this process, the protection of individual freedoms often remains underdeveloped.

European legal magazines hardly reflect the adaptations of law to social, political, and systemic needs for control in Europe. They typically - exceptions prove the rule-persist in a technical, dogmatic, or at best legal comparative approach. But precisely this remains superficial when it ignores both the respective legal functions in a changing societal structure and the historical-political background of laws, their genesis, and their application. On the European legal magazine market, legal developments are in the best 
cases looked at historically - without critical analysis. At the worst, the market is at the same time a forum for political consulting and offers a place for institutional interests which only use science as a tool. The law, its principles, and its control problems are neither socio-scientifically, economically, nor philosophically reflected upon. In Europe it is urgently necessary, however, that the foundations of law, its genesis and conditions of legitimacy as well as its consequences or lack thereof are ascertained. There is an irrefutable European need - even a demand - for open, comprehensive, informed, and interested critique of European law.

Institutions such as the European Commission evaluate the effects of European law and declare that there is a need for consultation. In the framework of EU-financed research, ideas on European jurisprudence are examined. Institutions, however, do not understand law as critical and autonomous but as an advisory science. The problem is that this functional external perception seems to have long since become the self-definition of European legal science. It does not remain with empirically-informed consulting, however: It does not only consult but functions as a source of legitimacy, thereby losing the critical distance to its object of research. A "Critical Quarterly" at the European level fills the gap by confronting institutionally-guided research skeptically, critically, but also constructively, and at the same time emphasizing scientific autonomy. It would provide a medium that would make critical originality and autonomous reflection possible. Last but not least, it would offer orientation for a European legal education which would go beyond the reduction of European universities to learning factories with quality controls. It would contradict bureaucratic intervention and economic preoccupation due to an incorrectly understood "Bologna system." Theory and European praxis in legislation, legal application, and science should work together in their European inter- and intradisciplinary aspects. Every critical perspective is welcome.

\section{Actors of Critique}

A European-oriented CritQ would not give up its strengths. Its editors and staff must represent different legal disciplines and critical approaches. They should not only represent the area of legal science but also legislation and legal execution. Ideally, it would also include non-legal professions, such as journalists, in active collaboration. It would turn to teachers as well as students in all of Europe. It would find itself in the university departments, but also in the judiciary, in institutions, legal offices, associations, and nongovernmental organizations. It is a good tradition that several editors of the CritQ are members of the German Federal Constitutional Court. In light of the dialogue between national constitutional courts and the European judiciary (European Court of Justice, European Court of Human Rights), it would be preferable to expand the list of editors to include important persons in European jurisprudence. The theory-praxis approach would thus be expanded throughout Europe, if legal scientists from many disciplines would get involved. The German legal circle alone can hardly carry an intra- and interdisciplinary critical approach. It would be a boon to insights and creativity to bring in methods, theories, and knowledge of the functions of law in various systems. It would thus lend itself to CritQ to motivate editors and staff members from across legal cultures and in particular to bring in the English and French legal circles. What has informally 
long been the practice of the current editors would be recognized European-wide as "peer review" articles. As little conformity as can be seen in the economically reduced perspective of evaluators, so sustainably and effectively could CritQ win and maintain its position in Europe if this procedure would be formally established and multiplied by European editors and staff members.

\section{Languages}

The European public - some deny it exists - is conveyed, if at all, by language. Critical approaches are articulated differently depending on the chosen language, and the differences themselves, once revealed, can offer a new critical approach. We make critique easier if it is expressed in the language closest to the critic, and we make a public possible by allowing and making room for communication differences in critique. The CritQ should make it possible in the future to publish articles in German, English, and French. In order to assist in understanding, an abstract in English would be a possibility. A multilingual body of editors located in different legal cultures could vouch for the originality and quality of the submitted articles. 